\title{
Application Article \\ Design of Novel S-Shaped Quad-Band Antenna for MedRadio/WMTS/ISM Implantable Biotelemetry Applications
}

\author{
Chih-Kuang Wu, ${ }^{1}$ Tsung-Fu Chien, ${ }^{2}$ Chin-Lung Yang, ${ }^{1}$ and Ching-Hsing Luo ${ }^{3}$ \\ ${ }^{1}$ Department of Electrical Engineering, National Cheng Kung University, Tainan 701, Taiwan \\ ${ }^{2}$ Department of Electrical Engineering, Southern Taiwan University, Tainan 710, Taiwan \\ ${ }^{3}$ Department of Electrical Engineering and Institute of Nanotechnology and Microsystems Engineering, \\ National Cheng Kung University, Tainan 701, Taiwan \\ Correspondence should be addressed to Chin-Lung Yang, cyang@mail.ncku.edu.tw \\ Received 8 April 2012; Revised 31 May 2012; Accepted 3 June 2012 \\ Academic Editor: Hon Tat Hui
}

Copyright () 2012 Chih-Kuang Wu et al. This is an open access article distributed under the Creative Commons Attribution License, which permits unrestricted use, distribution, and reproduction in any medium, provided the original work is properly cited.

\begin{abstract}
A novel S-shaped quad-band planar inverted-F antenna (PIFA) is proposed for implantable biotelemetry in the Medical Device Radiocommunications Service (MedRadio) band (401-406 MHz), Wireless Medical Telemetry Service (WMTS) band (1427$1432 \mathrm{MHz}$ ), and industrial, scientific, and medical (ISM) bands $(433-434 \mathrm{MHz}$ and $2.4-2.4835 \mathrm{GHz}$ ). The proposed antenna reveals compact dimension of $254 \mathrm{~mm}^{3}\left(10 \times 10 \times 2.45 \mathrm{~mm}^{3}\right)$ and is composed of three substrates and a superstrate, which are constructed from an S-shaped radiator (layer 1) and two twin radiators of spiral structures (layer 2 and layer 3). The optimal antenna characteristics were measured in the ground pork skin, and the measured bandwidths are $150 \mathrm{MHz}$ for the MedRadio and ISM bands $(433 \mathrm{MHz}), 52 \mathrm{MHz}$ for the WMTS band, and $102 \mathrm{MHz}$ for the ISM band $(2.4 \mathrm{GHz})$, respectively. The characteristics of proposed antenna are enough to support the applications of implantable body area networks (BAN) for biotelemetry and can completely cover main available frequency bands of BAN for biotelemetry below $3 \mathrm{GHz}$.
\end{abstract}

\section{Introduction}

Recently, researches of the implantable biotelemetry for early diagnosis of diseases and monitoring various physiological parameters had been reported. For such a biotelemetry system, these implantable antennas are applied to establish wireless communication links between implantable medical devices and exterior instruments for biotelemetry applications. These wireless communication links were operated at several frequency bands, and all these bands were presented in body area networks (BANs) [1]. In addition, in recent years, as an emerging ICT technology, BAN had caught significant attention. One of the many applications of BAN is in medical environment where conditions of patients are continuously monitored in real time. The range of medical device and systems being implanted into the human body is increasing rapidly. Among literatures, an intraocular implantable antenna [2] and a conformal ingestible capsule antenna [3] were investigated at Wireless Medical Telemetry Service (WMTS) band $(1.4 \mathrm{GHz})$. The implantable antenna for intracranial pressure (ICP) monitoring [4] and Implantable slot dipole conformal flexible antenna [5] were presented for industrial, scientific, and medical (ISM) band $(2.45 \mathrm{GHz})$. Planar antennas operating at the Medical Implant Communication Service (MICS) band (402$405 \mathrm{MHz}$ ) were discussed in [6-8]. Rectenna application of miniaturized implantable antenna [9] was developed for MICS band and two ISM bands (433 MHz and $2.4 \mathrm{GHz})$. Furthermore, an implantable antenna with pyramidal structure operating at Medical Device Radiocommunications Service (MedRadio) band (401-406 MHz) and ISM band $(2.4 \mathrm{GHz})$ was performed in [10]. However, as mentioned above, there are no results of research that can completely cover main available frequency bands of BAN for biotelemetry below $3 \mathrm{GHz}$. In addition, the Federal Communications 
Commission (FCC) created the MedRadio Service incorporating the existing MICS band and including the adjacent "wing" bands at 401-402 MHz and 405-406 MHz.

Therefore, design of an antenna with multiband and good radiating performance suitable for implanting into human body has already become a big challenge for designers. In the past literatures, for effectively reducing the volume of implantable antennas, most of the implantable antennas were designed by the uses of planar inverted- $F$ antenna (PIFA) structures $[4,6-9,11]$. Hence, in this paper, to meet the requirements of quad band, a PIFA antenna with Sshaped and two stacked twin spiral stripes was constructed on three layer substrates to lengthen effective current path. Meanwhile, a superstrate was also tightly covered on the top of proposed antenna for avoiding tissue erosion. But in [79], for lengthening the current path, the authors used feed point to connect layer 1 and layer 2. However, unlike these reports, we connected layer 1 with layer 2 via short pin and connect feed point with layer 2 directly to excite more modes and tune the impedance matching.

The proposed antenna with S-shaped and two stacked twin spiral stripes can excite four resonant frequencies which were at MedRadio band, WMTS band, and two ISM bands. The details of proposed antenna design and tuning mechanism will be discussed in Section 2. For verifying multiband implantable antenna, the emulating tissue had been developed, such as skin gel [11] and minced pork leg [6]. In this paper, owing tothat the characteristics of pork skin are more similar to human skin, ground pork skin was adopted as the emulated human tissue to verify the quad-band implantable antenna and the measured results were investigated. In addition, the electrical properties of ground pork skin will be shown in Section 3. Moreover, the simulated $10 \mathrm{~g}$ averaged specific absorption rate (SAR) satisfies the limitation of the American National Standards Institute (ANSI/ IEEE) for short-distance biotelemetry [12]. Detail results of the proposed antenna structure were simulated and measured in the quad band and presented in Section 4 .

\section{Antenna Design}

2.1. Structure of Antenna. Using the Ansoft simulation software high-frequency structure simulator (HFSSTM), a novel quad-band antenna was designed for the biotelemetry applications (MedRadio/WMTS/ISM). As shown in Figure 1, the proposed antenna is constructed with four-layered stack structures, the substrate and superstrate are all Rogers 3210 with the thickness of $0.635 \mathrm{~mm}$, loss tangent of 0.0027 , and dielectric constant of 10.2. The proposed antenna is composed of a ground plane, three radiating elements (layer 1, layer 2 and layer 3), three substrate layers, and a superstrate layer. In addition, the layer 1 is a radiator of S-shaped stripe, and layer 2 and layer 3 are twin radiators of spiral stripes structure. The feed point is directly connected to lower part of layer 2, the short pin connect layer 1 , and the upper part of layer 2. Layer 1 and the lower part of layer 2 are also connected through via 1 . The lower part of layer 2 and layer 3 are connected through via 2 , and the upper part of layer 2 and layer 3 are connected through via 3 .
However, for the purpose of tuning the impedance matching of the proposed antenna, the dimension of upper part of spiral structure in layer 3 (denoted as $t$ ) is chosen to tune the impedance matching of MedRadio band. And the dimension of lower part of spiral structure in layer 2 (denoted as $f$ ) is chosen to tune the impedance matching of two ISM bands. Besides, the hook-shaped radiator located on the lower part of layer 3 can be considered as an open capacitive tuning stub. Hence, by varying the length of hook (denoted as $s$ ), the impedance matching of WMTS band can be tuned.

2.2. Characteristics of Antenna. Figure 2 shows the simulated surface current distribution for the proposed antenna. It can be seen from Figure 2(a) that the current-flow path excites a fundamental resonant frequency to cover MedRadio band (401 MHz). Moreover, from the surface current distribution of Figure 2(b), it can be seen that the current-flow path excites another fundamental resonant frequency to cover ISM band ( $433 \mathrm{MHz})$. Consequently, utilizing the S-shaped with stacked spiral strip on PIFA structure can excite dual resonant frequencies and that can achieve wider bandwidth by the combination of the two close resonant frequencies [6]. Hence, that can obtain wider bandwidth of $168 \mathrm{MHz}(320$ $488 \mathrm{MHz}$ ) at a return loss of $10 \mathrm{~dB}$ to cover MedRadio band $(401 \mathrm{MHz})$ and ISM band $(433 \mathrm{MHz})$.

Moreover, from the surface current distribution of Figure 2(c), it can be found that two current null exist in the current-flow path, this confirms that the resonant frequency (at WMTS band) is the higher-order mode of $433 \mathrm{MHz}$ in Figure 2(b). Furthermore, from the surface current distribution of Figure 2(d), three current null can be found in the current-flow path, this confirms that the mode (at ISM band) is also the higher order mode of $433 \mathrm{MHz}$ in Figure 2(b).

2.3. Principle of Tuning Antenna. As shown in Figure 1, at the upper part of layer 3, it is constructed as a capacitive loading [13] and simulated return loss of the proposed antenna implanting into pork skin with various $t$ is shown in Figure 3. Clearly, the resonant frequency and bandwidth at MedRadio band $(401 \mathrm{MHz})$ can be adjusted and enhanced through changing the magnitude of $t$. Meanwhile, simulated return loss of the proposed antenna implanting into pork skin with various position of feed point (parameter $f$ ) is shown in Figure 4. Obviously, the position of feed point can determine the resonance of two ISM bands $(433 \mathrm{MHz}$ and $2.4 \mathrm{GHz}$ ) and enhance the impedance matching and bandwidth for ISM band ( $433 \mathrm{MHz})$. And the ISM band $(2.4 \mathrm{GHz})$ is the higher order mode of ISM band $(433 \mathrm{MHz})$. However, it is a convenient tuning mechanism for ISM band $(433 \mathrm{MHz})$ and ISM band $(2.4 \mathrm{GHz})$ by changing the position of feed point (parameter $f$ ). Therefore, the optimal parameters $(t=5.5 \mathrm{~mm}, f=2.2 \mathrm{~mm})$ were obtained for achieving dual-resonant frequencies of $347 \mathrm{MHz}$ and $441 \mathrm{MHz}$, respectively. The wide bandwidth of $168 \mathrm{MHz}$ $(320-488 \mathrm{MHz})$ is achieved owing to the combination of the two close resonant frequencies. In addition, changing the magnitude of parameter $s$ of hook-shaped tuning stub 


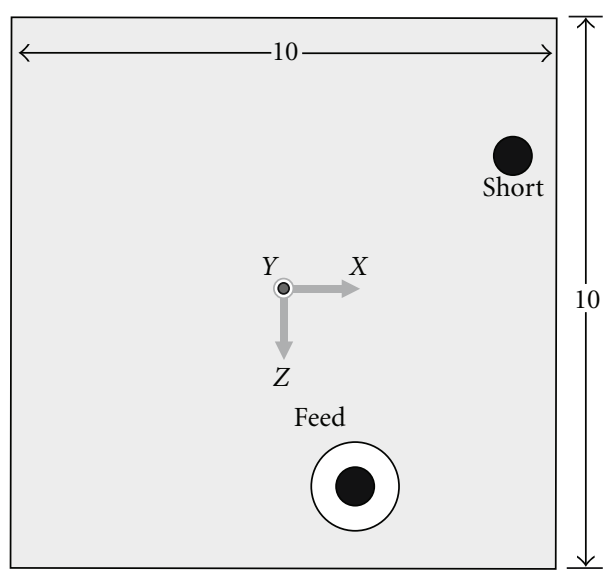

Ground

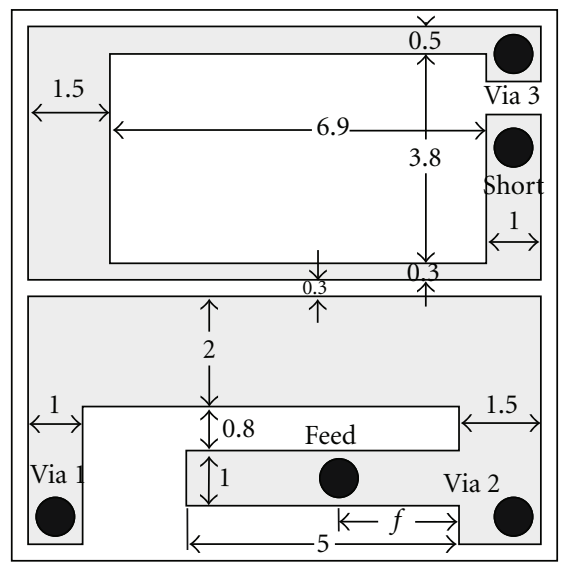

Layer 2

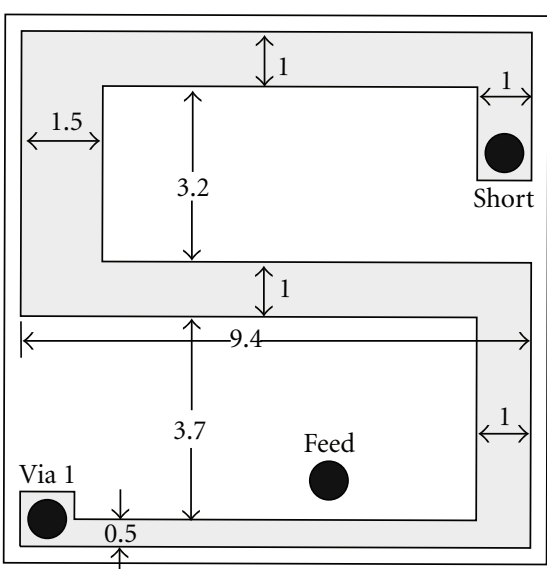

Layer 1

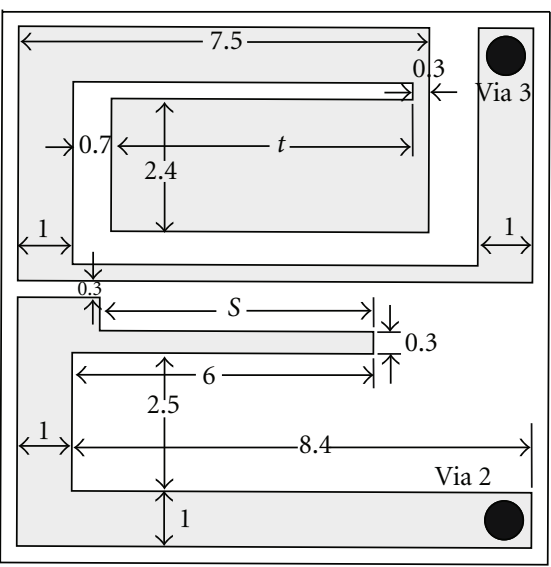

Layer 3

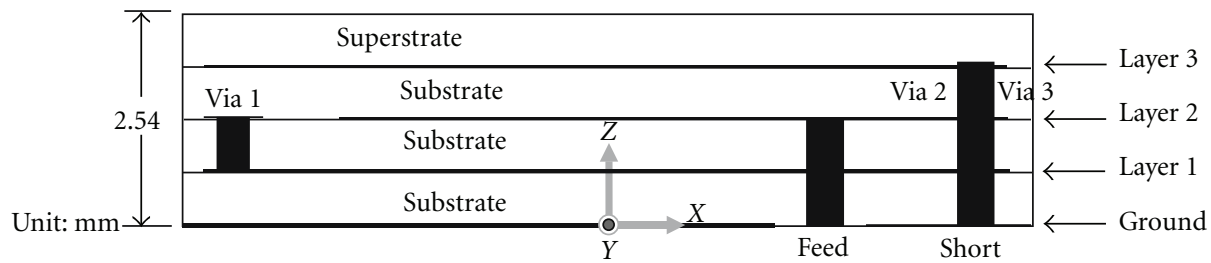

FIGURE 1: Geometry of the proposed antenna.

can change capacitance. As shown in Figure 5(a), for WMTS band $(1.427 \mathrm{GHz})$, as the magnitude of parameter $s$ increases progressively, the inductive impedance will gradually shift to the capacitive impedance. As shown in Figure 5(b), for the resonant frequency of WMTS band, changing the magnitude of $s$ is an effective tuning method, and the behavior of resonance shifting does not affect other two resonance frequencies of ISM band. Hence, the impedance matching can be improved by using an open capacitive stub which connects in shunt with the spiral structure of lower part of layer 2. Therefore, the optimal parameter $(s=5.5 \mathrm{~mm})$ was obtained for achieving resonant frequency of WMTS band $(1.427 \mathrm{GHz})$. In addition, adjusting the magnitude of $s$ can also tune the resonant frequency to $1.395-1.4 \mathrm{GHz}$, which is another spectrum block of WMTS band. Thus, the WMTS band of proposed antenna can be tuned to demanded spectrum block through this tuning mechanism. The four resonances can be fine tuned by varying the lengths of all spiral stripes to increase or decrease the effective length of current path and do impedance matching.

2.4. Experiment Setup. The simulated and measured environment of the proposed implantable antenna is embedded in the container $\left(55 \times 55 \times 20 \mathrm{~mm}^{3}\right)$ filled with the ground pork skin. In addition, the proposed antenna is placed at $4 \mathrm{~mm}$ [14] in depth inside the container. Furthermore, the coaxial cable is fixed in the cover of container for fixing the embedded depth in the container. The detailed structure and dimension of the container are shown as Figure 6. The measured $S_{11}$ values were obtained by the use of the Agilent 8753E network analyzer. And the RF signal generator (SMC 100A) and spectrum analyzer (HP N9304B) were used to measure the received power. As shown in Figure 7, in 

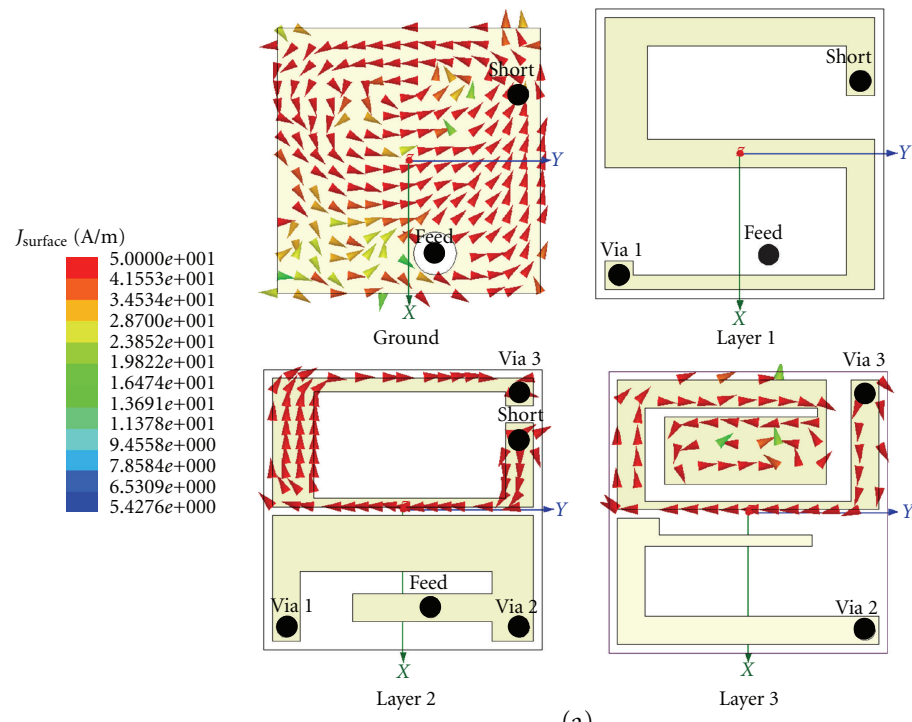

(a)

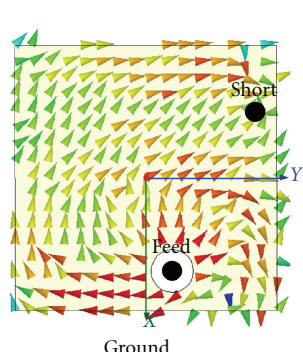

Ground

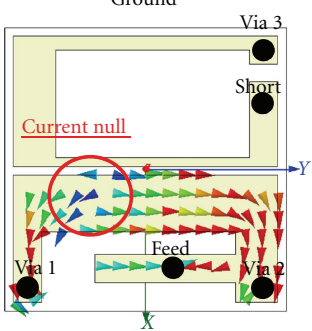

Layer 2

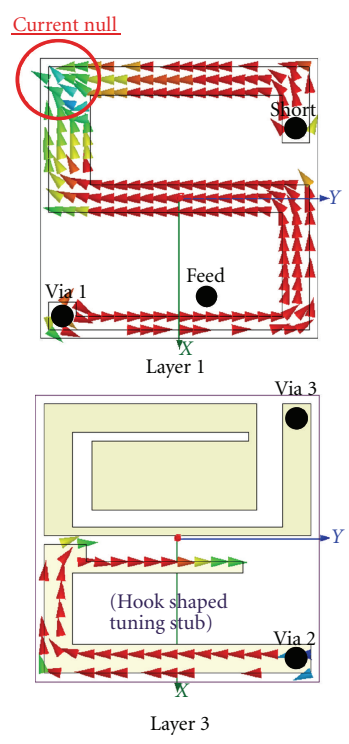

(c)

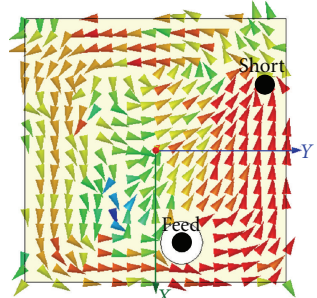

Ground

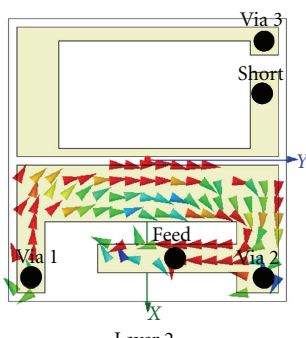

Layer 2

(b)

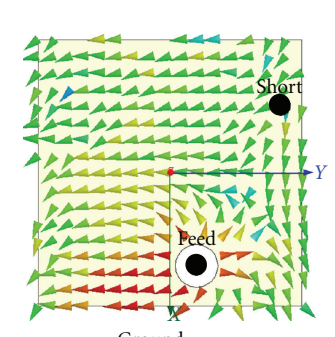

Ground

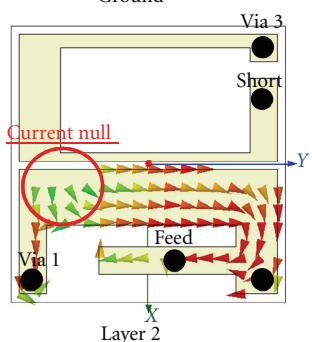

(d)
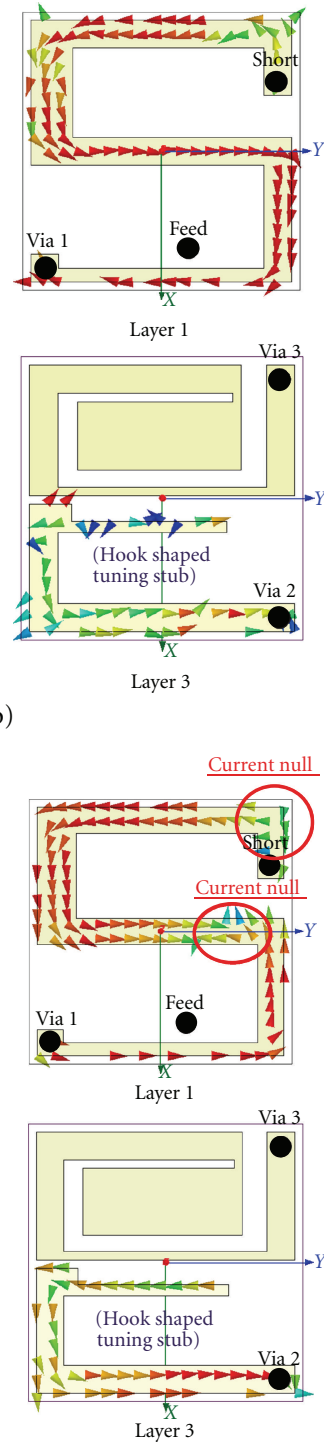

Layer 1

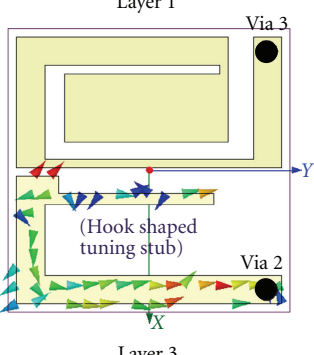

Figure 2: The simulated surface current distribution of the proposed antenna at (a) MedRadio band (401 MHz), (b) ISM band (433 MHz), (c) WMTS band (1.427 GHz), and (d) ISM band $(2.4 \mathrm{GHz})$.

a real environment, the communication link between the implanted proposed transmitting antenna and the onequarter wavelength exterior receiving monopole antenna was setup.

\section{The Electrical Properties of Ground Pork Skin}

Because the proposed antenna needs to be embedded inside emulating tissue to verify the characteristics of implant for biomedical telemetry, the specifications of emulating tissue must be similar to realistic human tissue for measurement of implantable antenna. In order to develop a test environment for multiband operation, skin gel [11] and pork leg [6] had been introduced for emulating skin tissue. However, for verifying the multiband antenna, the development of skin gels is quite inconvenient due to that one skin gel can only used for one special band. And the relative permittivity of pork leg is much higher than that of human skin, and the conductivity of pork leg is also much higher than that of human skin and muscle.

It measures the relative permittivity and conductivity of ground pork skin in a container, whose volume is $120 \times$ $120 \times 45 \mathrm{~mm}^{3}$, by using Agilent 85070 E dielectric probe kit and Agilent 8753E network analyzer. The relative permittivity and conductivity of the ground pork skin (the test tissue) are measured from $0.1 \mathrm{GHz}$ to $3.1 \mathrm{GHz}$ for 301 frequency points. The comparison of relative permittivity and conductivity of the pork skin, skin, and muscle [15-17] 


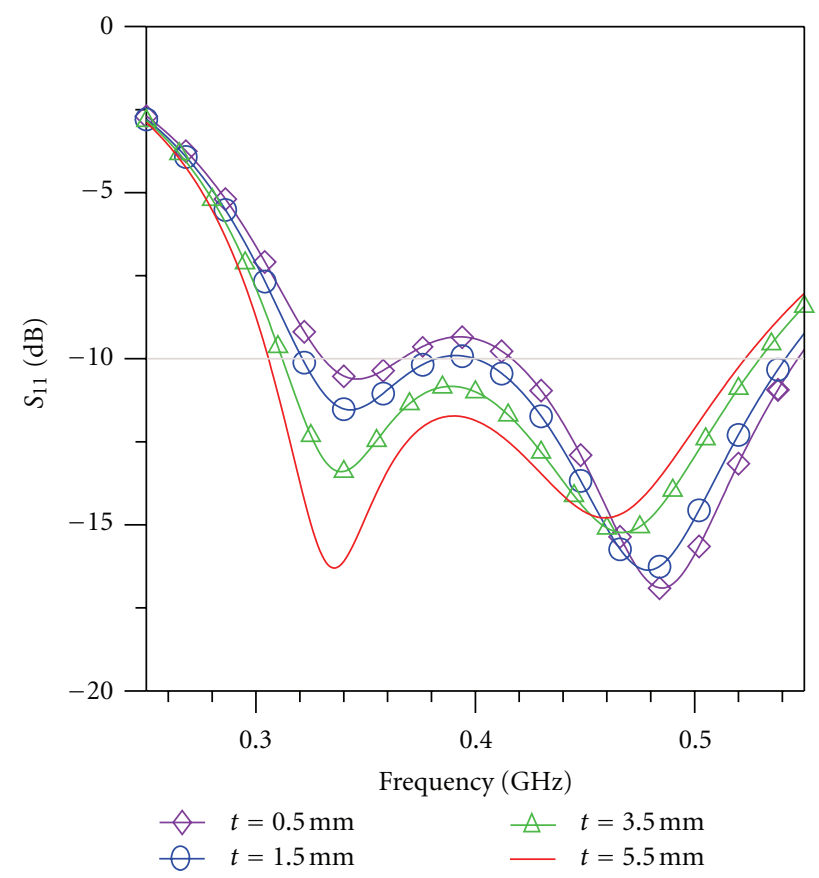

FIgURE 3: Simulated return loss for parameter of $t$ in pork skin.

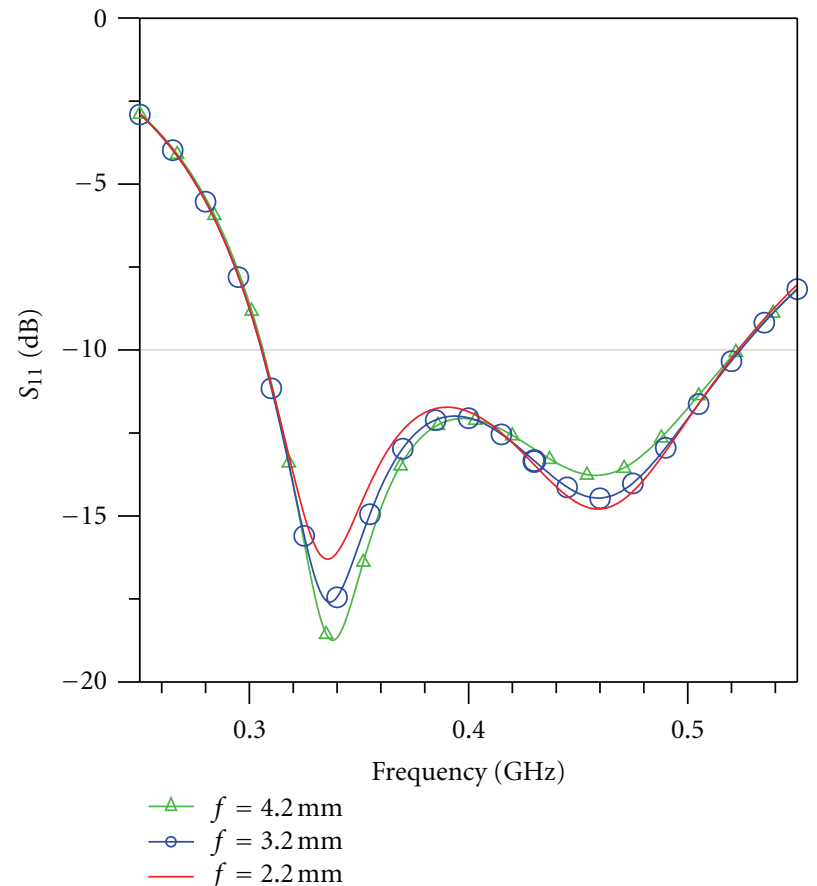

(a)

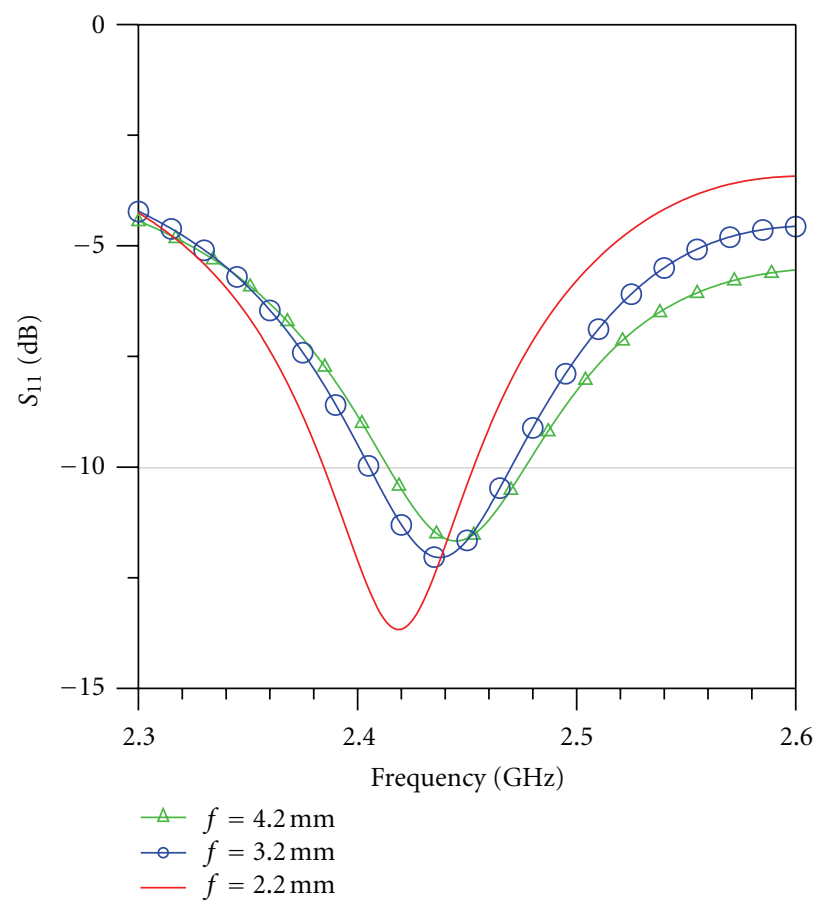

(b)

Figure 4: Simulated return loss for parameter of $f$ in pork skin (a) at ISM (433 MHz) band, (b) at ISM (2.4 GHz) band.

is shown in Figures 8(a) and 8(b). And the variability in the relative permittivity and conductivity of skin, muscle, and pork skin at MedRadio band, WMTS band, and two ISM bands is listed in Table 1. It can be found that the permittivity of ground port skin is close to human skin and very suitable to act as an emulating tissue. In addition, the simulated return loss of proposed antenna implanted into pork skin and skin is shown in Figure 9, which shows that the simulated results are consistent in pork skin and skin. Hence, in this paper, the ground pork skin was adopted as the test tissue 
TABLE 1: Comparison of electrical properties of tissues at MedRadio, WMTS, and two ISM bands.

\begin{tabular}{lcccccccc}
\hline \multirow{2}{*}{ Tissues } & \multicolumn{2}{c}{ MedRadio $(401 \mathrm{MHz})$} & \multicolumn{2}{c}{ ISM $(433 \mathrm{MHz})$} & \multicolumn{2}{c}{ WMTS $(1.427 \mathrm{GHz})$} & \multicolumn{2}{c}{ ISM $(2.4 \mathrm{GHz})$} \\
& $\varepsilon_{r}$ & $\sigma(\mathrm{S} / \mathrm{m})$ & $\varepsilon_{r}$ & $\sigma(\mathrm{S} / \mathrm{m})$ & $\varepsilon_{r}$ & $\sigma(\mathrm{S} / \mathrm{m})$ & $\varepsilon_{r}$ & $\sigma(\mathrm{S} / \mathrm{m})$ \\
\hline Pork skin & 46.6 & 0.66 & 46.5 & 0.67 & 42.3 & 1.08 & 40.3 \\
Skin & 46.8 & 0.69 & 46.1 & 0.7 & 39.6 & 1.04 & 38.1 \\
Muscle & 57.1 & 0.79 & 56.9 & 0.89 & 54.1 & 1.15 & 52.8 \\
\hline
\end{tabular}

Relative permittivity: $\varepsilon_{r}$; conductivity: $\sigma$.

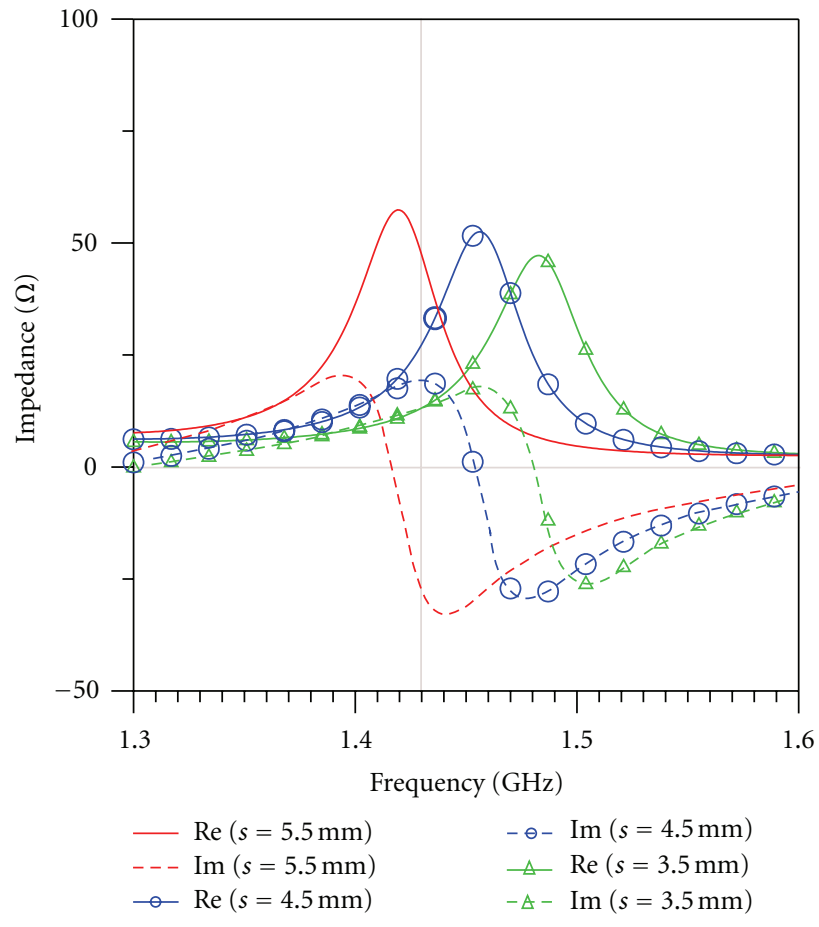

(a)

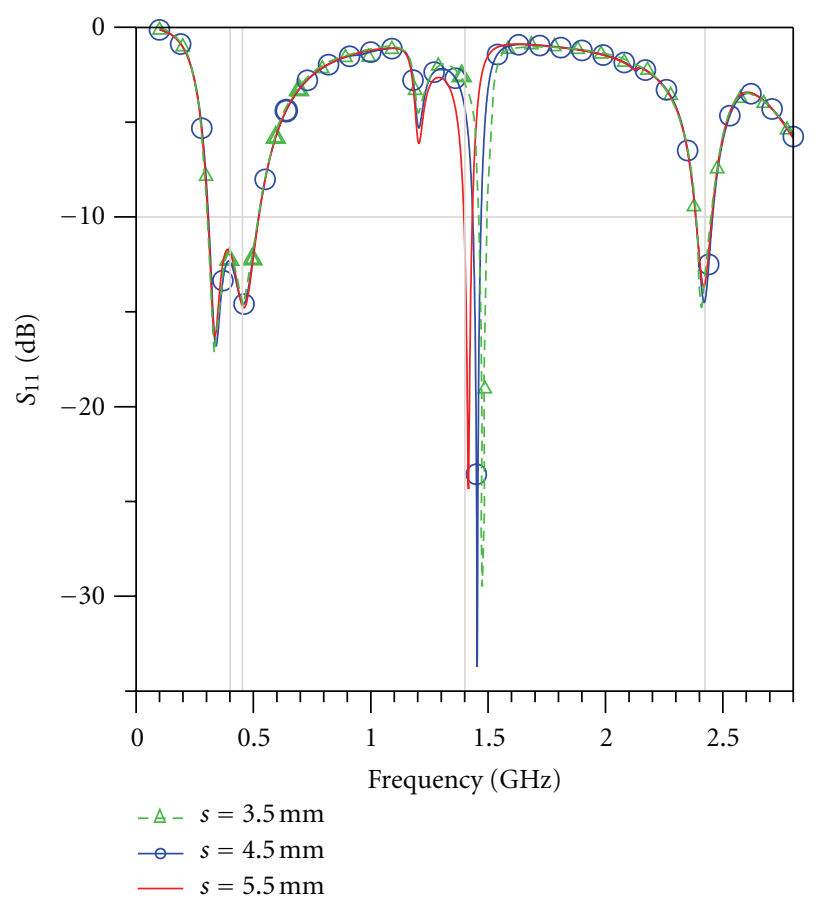

(b)

FIGURE 5: Simulated return loss for parameter of $s$ in pork skin (a) impedance, (b) $S_{11}$.

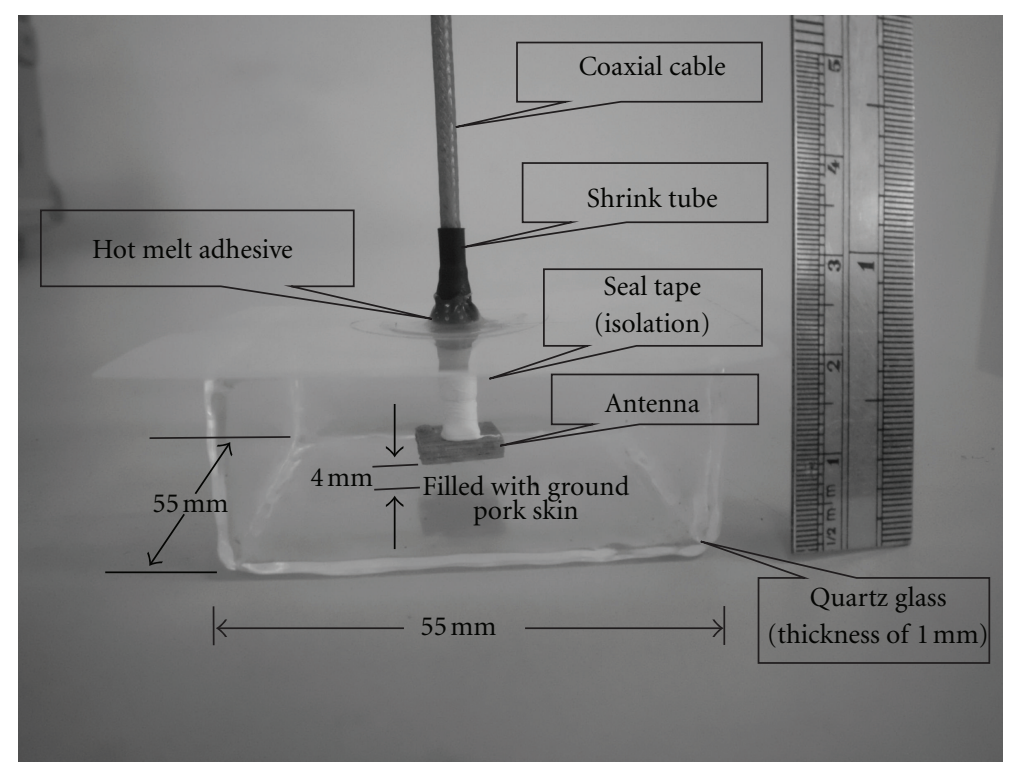

FIGURE 6: The structure and dimension of the container. 


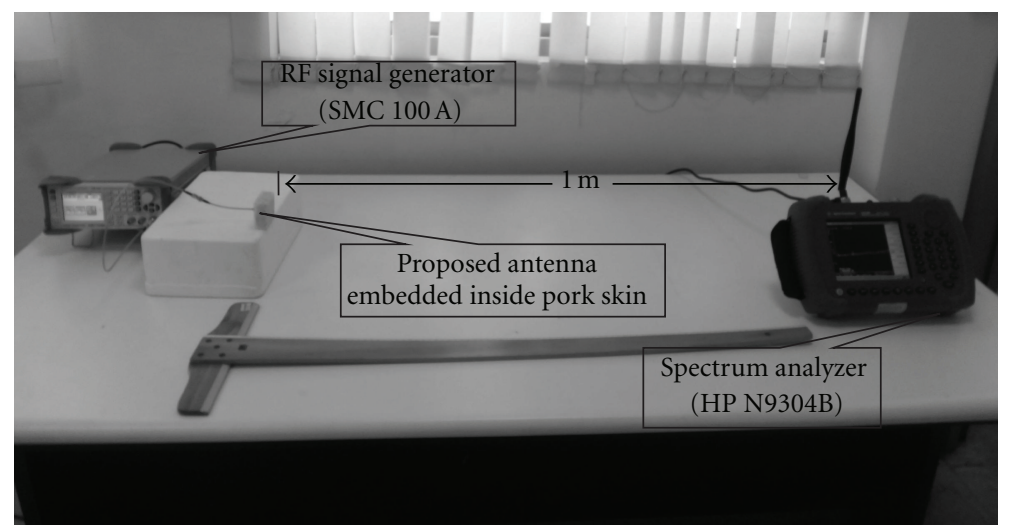

FIGURE 7: Measurement of received power at $1 \mathrm{~m}$ away from the proposed implanted antennas (delivered power is $1 \mathrm{~mW}$ ).

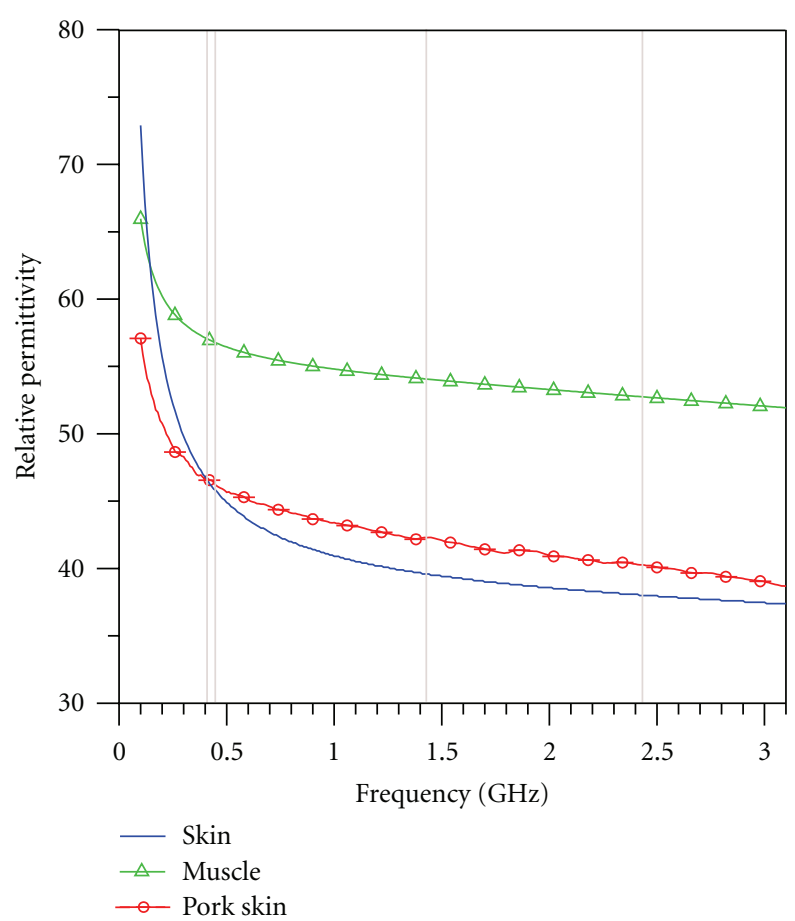

(a)

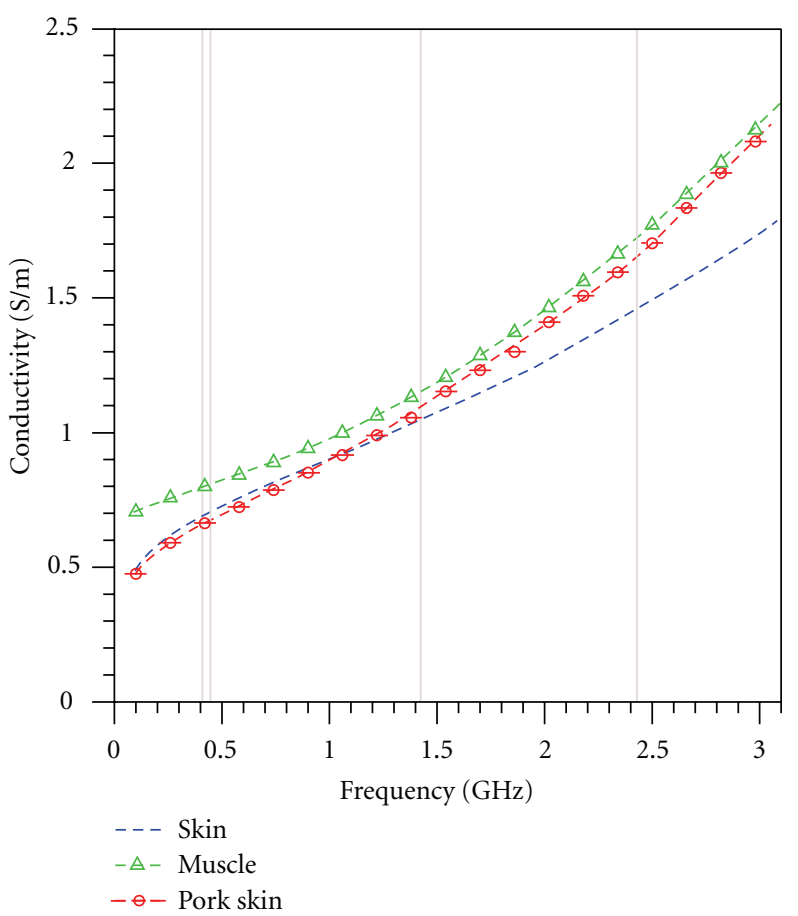

(b)

FIGURE 8: Comparison of human skin, human muscle, and pork skin: (a) relative permittivity and (b) conductivity.

due to that all the characteristics of the pork skin and skin are very similar.

\section{Results and Discussion}

The fabricated quad-band PIFA antenna is shown in Figure 10. As the proposed antenna was implanted into the ground pork skin (the emulated human tissue), the simulated and measured return loss results are shown in Figure 11. And good agreement can be found between the measured and simulated results. Moreover, the results of measured return loss reveal good impedance matching in the MedRadio band $(401 \mathrm{MHz})$ and the ISM band $(433 \mathrm{MHz})$ with impedance bandwidth of $150 \mathrm{MHz}(338-488 \mathrm{MHz})$, the WMTS band $(1.427 \mathrm{GHz})$ with impedance bandwidth of $52 \mathrm{MHz}(1.41-$ $1.462 \mathrm{GHz})$, and the ISM band $(2.4 \mathrm{GHz})$ with impedance bandwidth of $102 \mathrm{MHz}(2.373-2.475 \mathrm{GHz})$. The peek directivity, radiation efficiency, and peek gain results of proposed antenna are shown in Table 2.

In Figure 12, as the antenna was simulated implanted into the skin, the simulated three-dimension far-field peak gain is $-22 \mathrm{dBi}$ for $401 \mathrm{MHz},-23 \mathrm{dBi}$ for $433 \mathrm{MHz},-17 \mathrm{dBi}$ for $1.427 \mathrm{GHz}$, and $-16 \mathrm{dBi}$ for $2.4 \mathrm{GHz}$, respectively. Meanwhile, by using the Ansoft simulation software HFSS, the simulated $10 \mathrm{~g}$ averaged specific absorption rate (SAR) distribution of proposed antenna implanted into the skin is shown in Figure 13. Whereas the delivered power is assumed to 
TABLE 2: The peek directivity, radiation efficiency, and peek gain results of proposed antenna.

\begin{tabular}{lcccc}
\hline & MedRadio $(401 \mathrm{MHz})$ & ISM $(433 \mathrm{MHz})$ & WMTS $(1.427 \mathrm{GHz})$ & ISM $(2.4 \mathrm{GHz})$ \\
\hline Peek directivity & 0.33202 & 0.423772 & 1.99281 & 2.21578 \\
Radiation efficiency & 0.019269 & 0.0119228 & 0.00909009 & 0.0109045 \\
Peek gain & 0.00639769 & 0.00505254 & 0.0181148 & 0.024162 \\
\hline
\end{tabular}

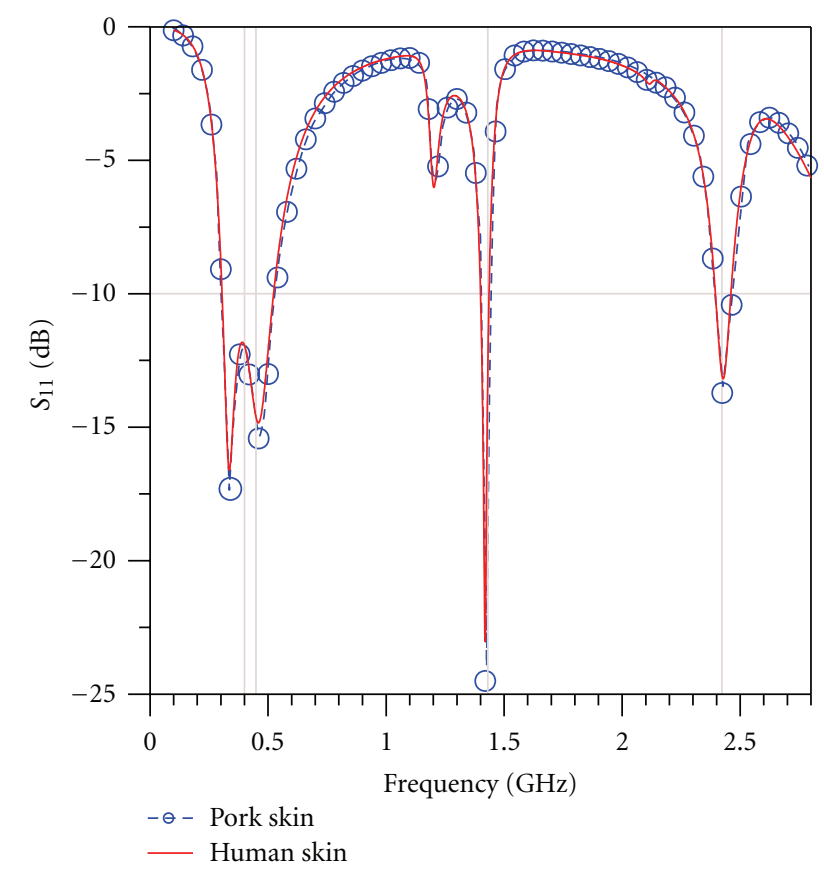

FIGURE 9: Simulated return loss of proposed antenna implanted into pork skin and skin.

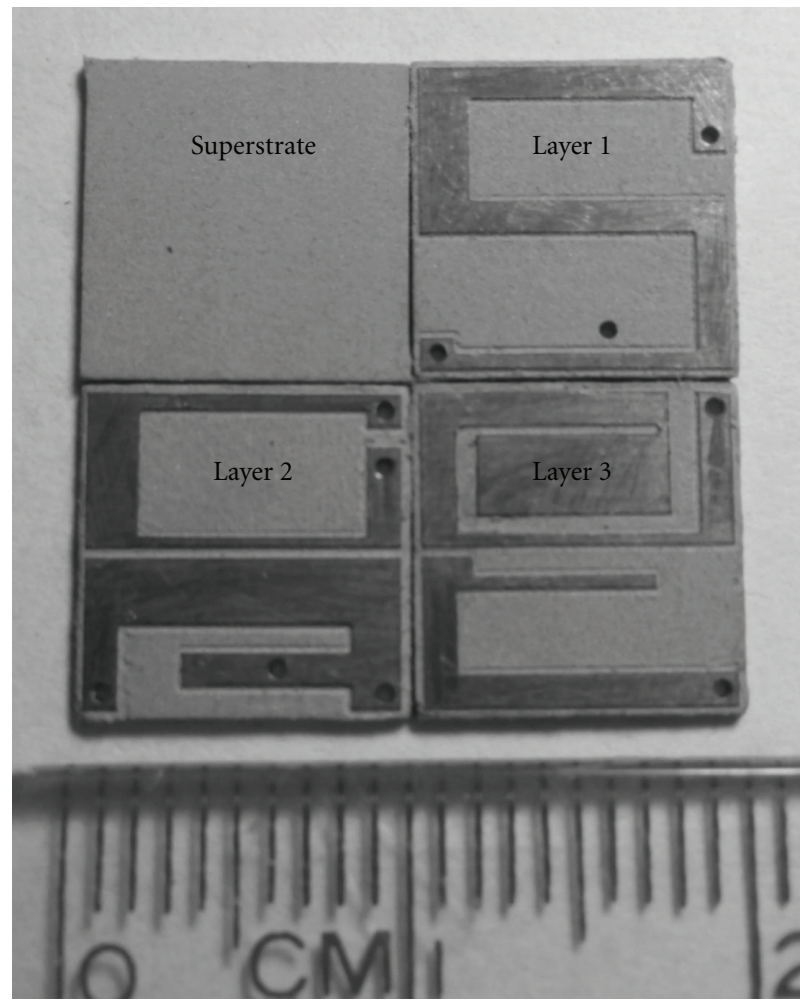

Figure 10: Fabricated quad-band implantable PIFA antenna. 


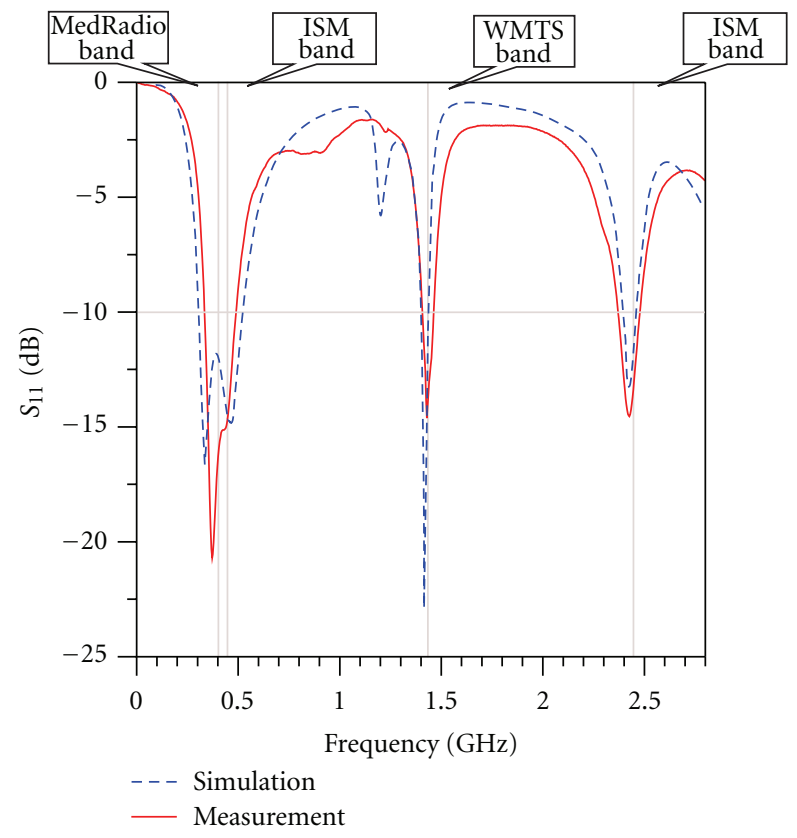

FIGURE 11: Simulated and measured return loss for the proposed antenna implanted in ground pork skin.

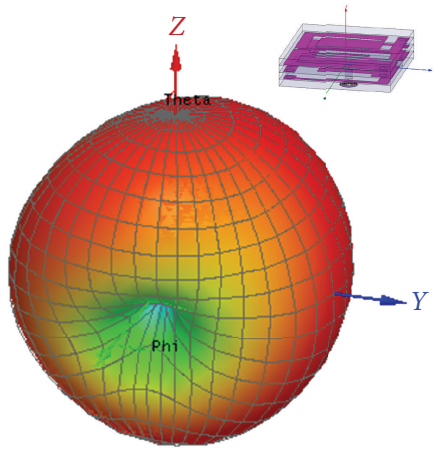

(a)

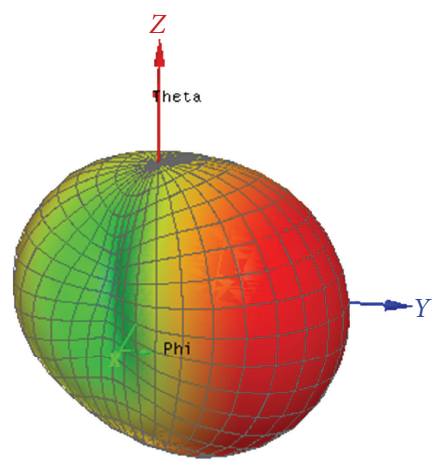

(c)
Total gain $(\mathrm{dB})$
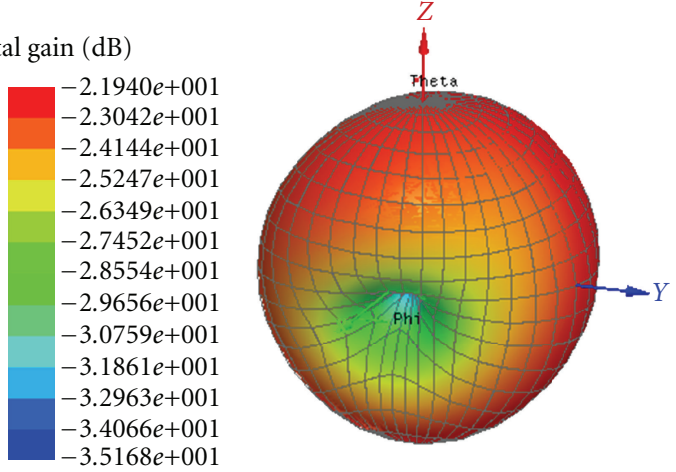

Total gain $(\mathrm{dB})$

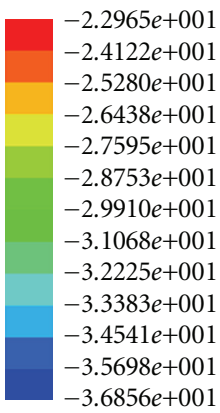

(b)

Total gain $(\mathrm{dB})$
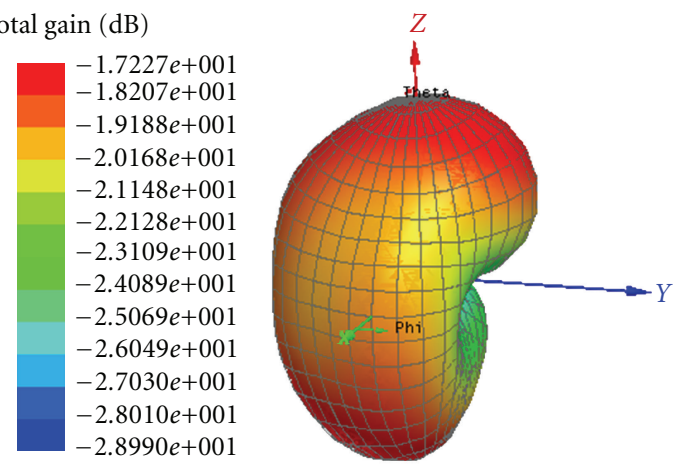

Total gain $(\mathrm{dB})$

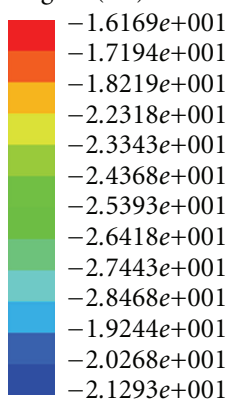

(d)

FIGURE 12: Simulated three-dimensional antenna radiation patterns (delivered power = $1 \mathrm{~W}$ ), (a) $401 \mathrm{MHz}$, (b) $433 \mathrm{MHz}$, (c) $1.427 \mathrm{GHz}$, and (d) $2.4 \mathrm{GHz}$. 
TABLE 3: Comparison of the measured received power between the proposed antenna and [14].

\begin{tabular}{|c|c|c|c|c|c|}
\hline Antennas & Delivere power $(\mathrm{mW})$ & Gain $(\mathrm{dBi})$ & Radiation efficiency & Distance $(\mathrm{m})$ & Receive power $(\mathrm{dBm})$ \\
\hline Reference [14] MICS (402 MHz) & 8.8 & N/A & $0.16 \%$ & 0.3 & -30 \\
\hline MedRadio $(401 \mathrm{MHz})$ & 1 & -22 & $1.93 \%$ & 1 & -51 \\
\hline ISM (433 MHz) & 1 & -23 & $1.19 \%$ & 1 & -50 \\
\hline WMTS (1.427 GHz) & 1 & -17 & $0.91 \%$ & 1 & -46 \\
\hline ISM $(2.4 \mathrm{GHz})$ & 1 & -16 & $1.1 \%$ & 1 & -44 \\
\hline
\end{tabular}

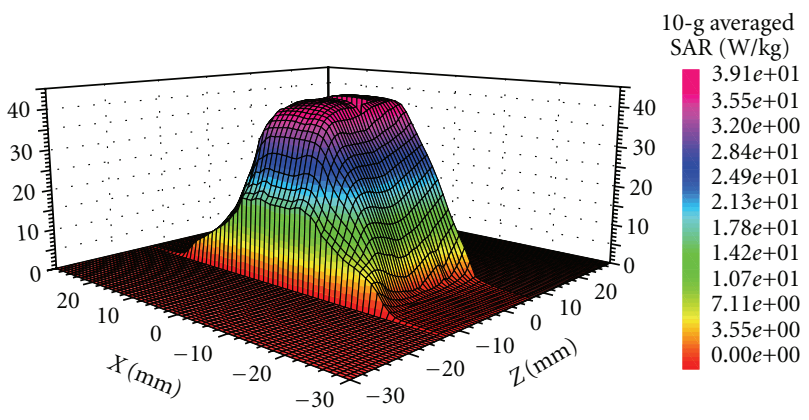

(a)

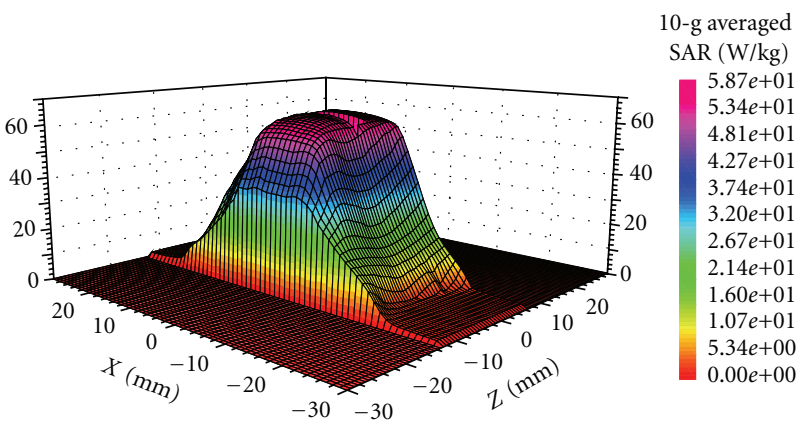

(c)

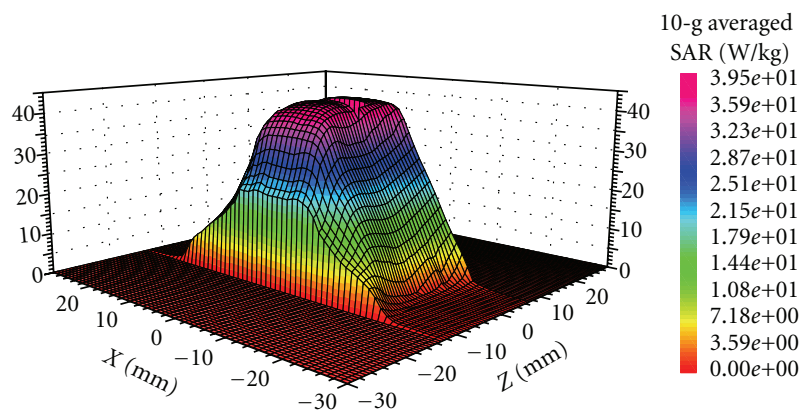

(b)

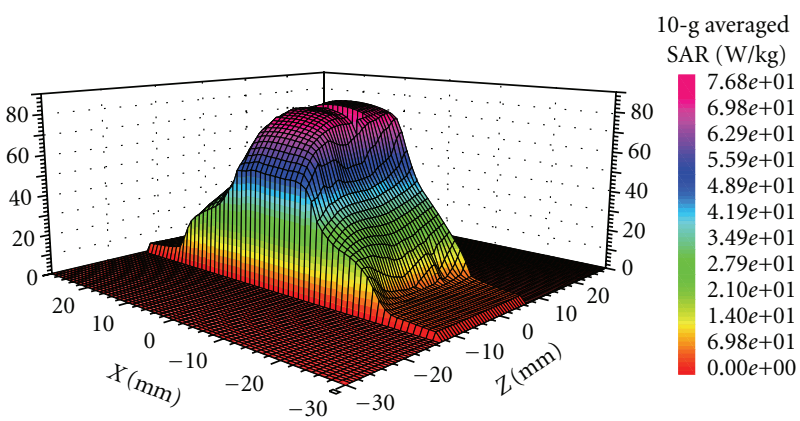

(d)

FIGURE 13: Simulated $10 \mathrm{~g}$ averaged SAR distribution (delivered power $=1 \mathrm{~W}$, SAR calibration line was placed at $Y=0 \mathrm{~mm}$ ), (a) $401 \mathrm{MHz}$, (b) $433 \mathrm{MHz}$, (c) $1.427 \mathrm{GHz}$, and (d) $2.4 \mathrm{GHz}$.

be $1 \mathrm{~W}$, the maximum simulated $10 \mathrm{~g}$ averaged SAR value is about $39.1 \mathrm{~W} / \mathrm{kg}$ at $401 \mathrm{MHz}, 39.5 \mathrm{~W} / \mathrm{kg}$ at $433 \mathrm{MHz}$, $58.7 \mathrm{~W} / \mathrm{kg}$ at $1.43 \mathrm{GHz}$, and $76.8 \mathrm{~W} / \mathrm{kg}$ at $2.4 \mathrm{GHz}$, respectively, which need to meet the regulated SAR limitation $(2.0 \mathrm{~W} / \mathrm{kg})$ restricted by American National Standards Institute (ANSI/IEEE) regulation for short-distance biotelemetry [12]. Therefore, the delivered power of proposed antenna must be reduced to less than $26 \mathrm{~mW}$, then that can satisfy the limitation of $2 \mathrm{~W} / \mathrm{kg}$ SAR for quad band in this paper.

As shown in Figure 7, in a real environment, the communication link between the implanted proposed transmitting antenna and the one-quarter wavelength exterior receiving monopole antenna was setup. As the communication link distance was $1 \mathrm{~m}$ and $1 \mathrm{~mW}$ was delivered to the proposed antenna, the experimental measured received power reveals about $-51 \mathrm{dBm}$ at $401 \mathrm{MHz},-50 \mathrm{dBm}$ at $433 \mathrm{MHz}$,
$-46 \mathrm{dBm}$ at $1.427 \mathrm{GHz}$, and $-44 \mathrm{dBm}$ at $2.4 \mathrm{GHz}$, respectively. In [14], the communication link was built between the implanted antenna and exterior dipole, and distance between two antennas is smaller than $30 \mathrm{~cm}$. As shown in Table 3, the radiation efficiency of proposed antenna is almost more than [14] ten times, and the delivered power of proposed antenna only about the one ninth of [14]. Moreover, the distance of this paper is more than [14] three times and the gain of the four bands of proposed antenna is remarkably high. Consequently, it can be concluded that the link budget of proposed antenna is enough to support the applications of multiband in the biotelemetry.

As listed in Table 4, compared to previous reports of implantable antennas, almost all the previous implantable antennas presented single $[2-8]$, dual $[10,11]$, and triple band [9] operations; however, only the proposed antenna 


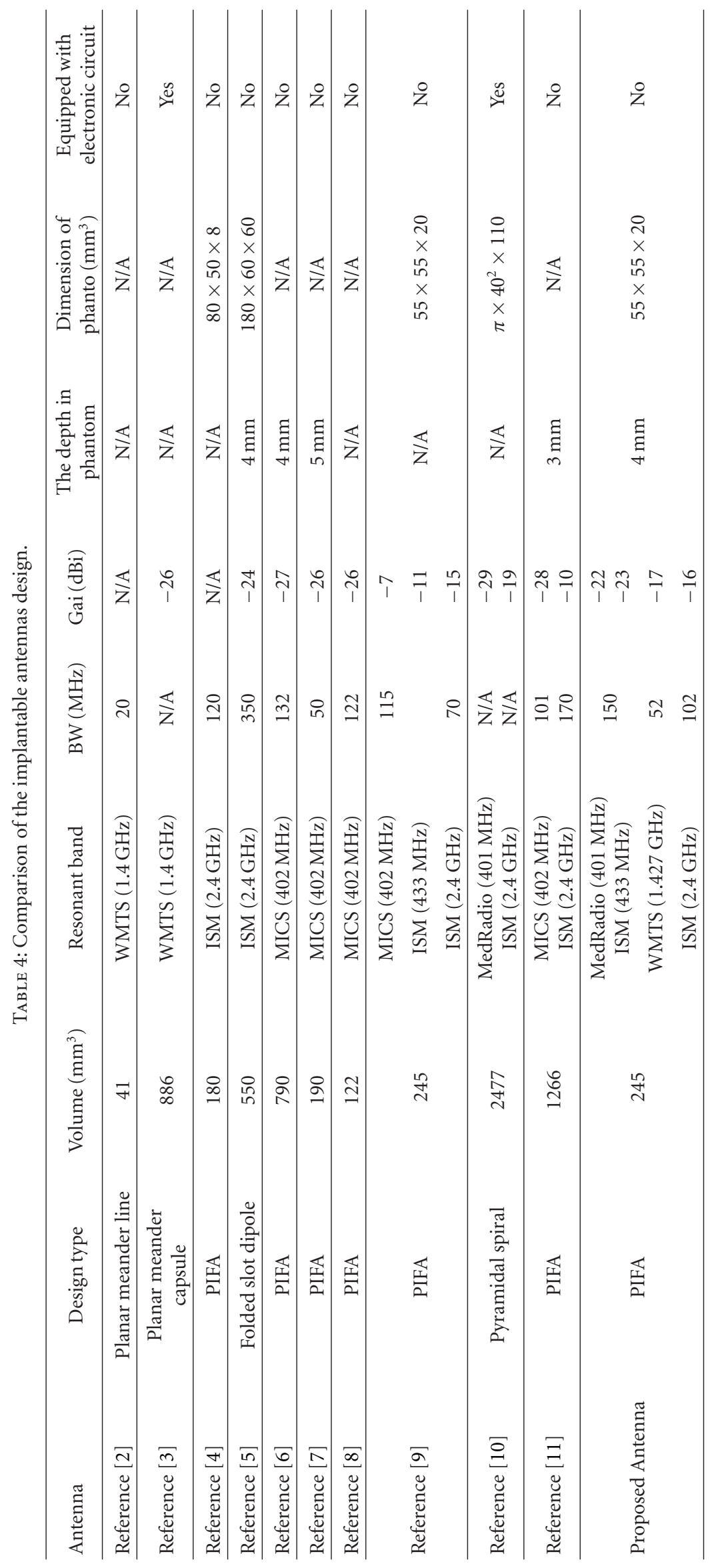


presents quad-band operation. Obviously,although the proposed quad-band antenna only occupies a volume of $254 \mathrm{~mm}^{3}\left(10 \times 10 \times 2.54 \mathrm{~mm}^{3}\right)$, the proposed antenna reveals wider bandwidth and higher gain than the previous designs of antenna.

\section{Conclusion}

A novel quad-band PIFA antenna is presented for biotelemetry, which can achieve a bandwidth of $150 \mathrm{MHz}$ for MedRadio $(401 \mathrm{MHz})$ and ISM $(433 \mathrm{MHz})$, a bandwidth of $52 \mathrm{MHz}$ for WMTS band $(1.427 \mathrm{GHz})$, and a bandwidth of $102 \mathrm{MHz}$ for ISM band $(2.4 \mathrm{GHz})$. Moreover, the results of $1 \mathrm{~g}$ averaged SAR distribution of proposed antenna meet the regulated SAR limitation restricted by ANSI/IEEE for these four bands. Furthermore, a reliable communication link with distance of $1 \mathrm{~m}$ has been setup and demonstrated. The proposed antenna can excite four resonance frequencies by changing the parameters $t, f$, and $s$ easily and further achieve precise frequency-controlling mechanism for quad-band operations. Finally, compared to the results in the past literatures, only the proposed antenna can completely cover main available frequency bands of BAN for biotelemetry below $3 \mathrm{GHz}$. Therefore, the proposed antenna is enough to support the applications of multiband implantable antenna for biotelemetry.

\section{Acknowledgment}

This work was supported by the National Science Council, Taiwan, under Grants of NSC 100-2220-E-006-012.

\section{References}

[1] H. B. Li, J. Schwoerer, Y. M. Yoon et al., IEEE 802.15.6 Regulation Subcommittee Report, 15-08-0034-08-0006-ieee802-15-6-regulation-subcommittee-report.doc.

[2] K. Gosalia, M. S. Humayun, and G. Lazzi, "Impedance matching and implementation of planar space-filling dipoles as intraocular implanted antennas in a retinal prosthesis," IEEE Transactions on Antennas and Propagation, vol. 53, no. 8 I, pp. 2365-2373, 2005.

[3] P. M. Izdebski, H. Rajagopalan, and Y. Rahmat-Samii, "Conformal ingestible capsule antenna: a novel chandelier meandered design," IEEE Transactions on Antennas and Propagation, vol. 57, no. 4, pp. 900-909, 2009.

[4] R. Warty, M. R. Tofighi, U. Kawoos, and A. Rosen, "Characterization of implantable antennas for intracranial pressure monitoring: reflection by and transmission through a scalp phantom," IEEE Transactions on Microwave Theory and Techniques, vol. 56, no. 10, pp. 2366-2376, 2008.

[5] M. L. Scarpello, D. Kurup, H. Rogier et al., "Design of an implantable slot dipole conformal flexible antenna for biomedical applications," IEEE Transactions on Antennas and Propagation, vol. 59, no. 10, pp. 3556-3564, 2011.

[6] C. M. Lee, T. C. Yo, F. J. Huang, and C. H. Luo, "Bandwidth enhancement of planar inverted-f antenna for implantable biotelemetry," Microwave and Optical Technology Letters, vol. 51, no. 3, pp. 749-752, 2009.
[7] W. C. Liu, F. M. Yeh, and M. Ghavami, "Miniaturized implantable broadband antenna for biotelemetry communication," Microwave and Optical Technology Letters, vol. 50, no. 9, pp. 2407-2409, 2008.

[8] W. C. Liu, S. H. Chen, and C. M. Wu, "Bandwidth enhancement and size reduction of an implantable pifa antenna for biotelemetry devices," Microwave and Optical Technology Letters, vol. 51, no. 3, pp. 755-757, 2009.

[9] F. J. Huang, C. M. Lee, C. L. Chang, L. K. Chen, T. C. Yo, and C. H. Luo, "Rectenna application of miniaturized implantable antenna design for triple-band biotelemetry communication," IEEE Transactions on Antennas and Propagation, vol. 59, no. 7, pp. 2646-2653, 2011.

[10] F. Merli, L. Bolomey, J. Zurcher, G. Corradini, E. Meurville, and A. K. Skrivervik, "Design, realization and measurements of a miniature antenna for implantable wireless communication systems," IEEE Transactions on Antennas and Propagation, vol. 59, no. 10, pp. 3544-3555, 2011.

[11] T. Karacolak, A. Z. Hood, and E. Topsakal, "Design of a dualband implantable antenna and development of skin mimicking gels for continuous glucose monitoring," IEEE Transactions on Microwave Theory and Techniques, vol. 56, no. 4, pp. 1001-1008, 2008.

[12] "IEEE standard for safety levels with respect to human exposure to radio frequency electromagnetic fields, $3 \mathrm{KHz}$ to 300 GHz," IEEE Standard C95.1-2005, 2005.

[13] C. R. Rowell and R. D. Murch, "A capacitively loaded PIFA for compact mobile telephone handsets," IEEE Transactions on Antennas and Propagation, vol. 45, no. 5, pp. 837-842, 1997.

[14] J. Kim and Y. Rahmat-Samii, "Implanted antennas inside a human body: simulations, designs, and characterizations," IEEE Transactions on Microwave Theory and Techniques, vol. 52, no. 8, pp. 1934-1943, 2004.

[15] C. Gabriel, S. Gabriel, and E. Corthout, "The dielectric properties of biological tissues: I. Literature survey," Physics in Medicine and Biology, vol. 41, no. 11, pp. 2231-2249, 1996.

[16] S. Gabriel, R. W. Lau, and C. Gabriel, "The dielectric properties of biological tissues: II. Measurements in the frequency range $10 \mathrm{~Hz}$ to $20 \mathrm{GHz}$," Physics in Medicine and Biology, vol. 41, no. 11, pp. 2251-2269, 1996.

[17] S. Gabriel, R. W. Lau, and C. Gabriel, "The dielectric properties of biological tissues: III. Parametric models for the dielectric spectrum of tissues," Physics in Medicine and Biology, vol. 41, no. 11, pp. 2271-2293, 1996. 

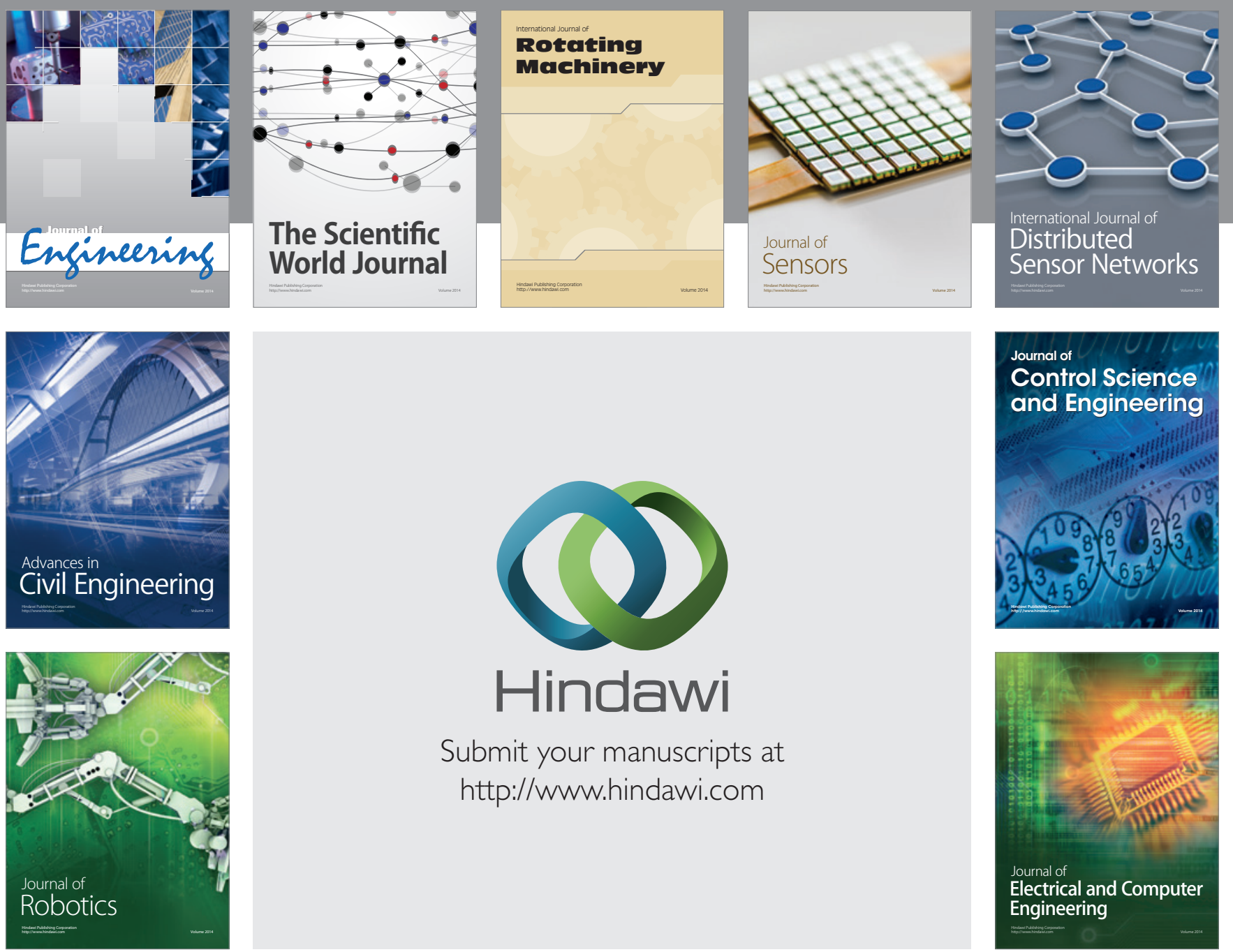

Submit your manuscripts at

http://www.hindawi.com
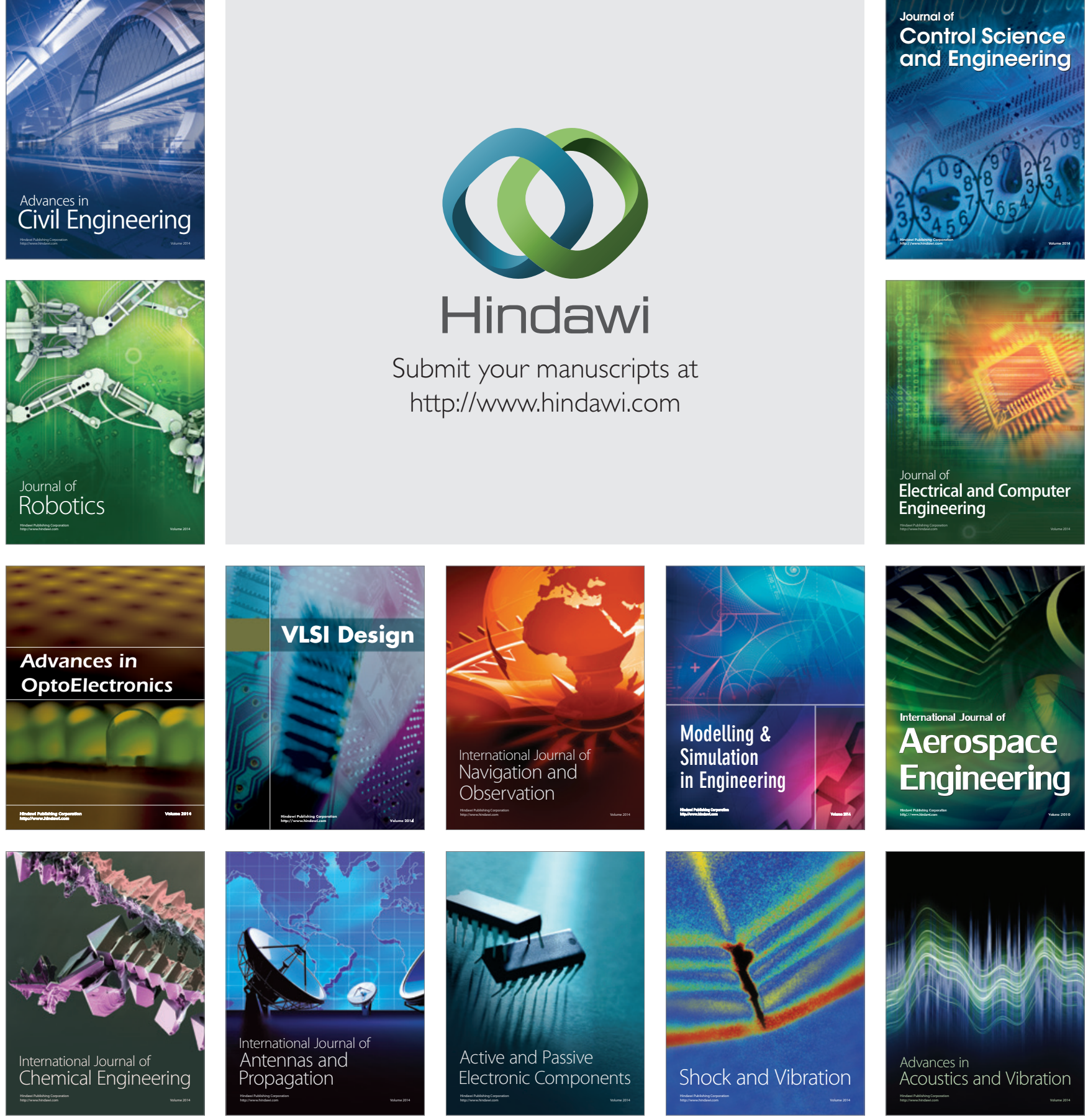